\title{
An optimal allocation of UPFC and transient stability improvement of an electrical power system: IEEE-30 buses
}

\author{
Ali Abdul Razzaq Altahir, Marwa M. Marei \\ Electrical and Electronic Engineering Department, University of Kerbala, Karbala, Iraq
}

\begin{tabular}{l}
\hline \hline Article Info \\
\hline Article history: \\
Received Dec 19, 2020 \\
Revised Apr 9, 2021 \\
Accepted May 21, 2021 \\
\hline
\end{tabular}

\section{Keywords:}

IEEE 30-buses

Modified PSO

Optimal allocation

Transient stability

Unified controller

\begin{abstract}
Recently, the expansion process of electrical networks has become crucial with the development of electrical systems. One of the active solutions to progress the performance of an electrical system is the usage of flexible AC transmission system (FACTS). As a new generation of telecommunications and power electronics technology, FACTS has provided a new viewpoint to increase the bearing capacity, better control the grid, and reduce costs. The unified power flow controller had a multi-purpose unit that could command the scenario of providing or consuming the power components and maintaining the bus voltage. The study's novelty resided in presenting a modified particle swarm optimization algorithm-based software system and applied a Newton-Raphson load flow solution to get the best solutions for optimal allocation of unified power flow controllers (UPFC). This study has focused on the functions of the UPFC electrical system with corresponding effects on transient stability. MATLAB software (Simulink/code) and excel sheet were performed on IEEE 30 buses as a case study. It has been shown the effectiveness of UPFC with fast response and autonomous command on the flow of power components. The dynamic response for stability improvement for some network buses had been verified to ensure the robustness of UPFC during a sudden disturbance in electrical load. The case study results illustrate that the number of UPFC increased with load increased by ( $14 \%$ and $21 \%)$.
\end{abstract}

This is an open access article under the CC BY-SA license.

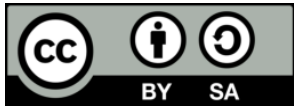

\section{Corresponding Author:}

Ali Abdul Razzaq Altahir

Electrical and Electronic Engineering Department

University of Kerbala, Collage of Engineering

Fraiha Campus, Karbala, 56001, Iraq

Email: ali.altahir@uokerbala.edu.iq

\section{INTRODUCTION}

Nowadays, there are some limitations in extending the power systems' transmission and generation grid to advance such systems. So, the optimization using the available capacity in the grid has been inevitable. The flexible AC transmission systems (FACTS) as a new generation of power electronics technology had provided a unique viewpoint to raise the bearing size, better control of the grid, and saving costs and energy. FACTS with the permanent application in the market change into the optimized power grid and optimal power flow, concertedly [1], [2]. The unified power flow controllers (UPFC) could command an active power as well as compensate a reactive power component. Reducing the costs of electrical generation and decreasing its losses in the grid is one of the benefits of UPFC [3]. UPFC is one of the FACTS generations. It is very flexible, and it commands the power components in the power system. It can do all compensations wherever it is needed. UPFC is a grouping of static synchronous compensator (STATCOM) and static synchronous series compensator (SSSC) that were linked by a direct current voltage. This device 
could control various use parameters of the power grid synchronously. These parameters usually include a line bus voltage, impedance, and phase angle. Controlling a power system is very complicated because it has a power line impedance of the transmitted, received voltage domain and the phase of this voltage. Transmission systems were designed with series or parallel reactive compensators or compensators accompanied by electromagnetic switches with voltage regulators and phase shift transformers to adjust the line impedance, reduce potential deviation and regulate the power grid. Power systems were designed concerning the extensive stable range to return from unexpected work condition such as physical error and generator or line disconnected [4].

The small way has many complexities and costly establishments. It is based on the direct relation between distribution generation in the microgrids and the main grids. Using the remote method requires having a good and safe communication system. The local way has two active and inactive modes. This method is active mode because it recognizes the islanding mode by intentionally creating a system disturbance according to system reaction. The constant trouble in the system is considered as the main disadvantage of this method. The inactive mode is based on measurement. It measures the local parameters such as voltage, frequency, total harmonic distortion, power frequency deviation rate, and power signal deviation rate. These values should be compared to identify the islanding mode threshold [5].

One of the grid's essential voltage controllers is a tap changer transformer that can be converted into an automatic potential controller. Thyristors are used for this purpose. D-UPFC is structurally different from UPFC. Its components contain a parallel transformer that supplies the input current and a series transformer that injects the chopper circuit's output voltage into the scheme. D-UPFC could control the voltage drop provided by a short circuit or substantial power connection to the grid. UPFC can be installed at the back of a power transformer or anywhere else in the grid [6].

The research presented in [7] examined the UPFC application as a limiter of error current. They added the control function to UPFC at the time of the error. It controls the real and imaginary power movement over the line in the regular operation of the grid. They are also used as the limiter of error flow in a time of the short circuit. Research in [8] investigates the excellent performance of fuzzy controllers in minimizing the fluctuations. After optimizing the fuzzy controllers designed by fuzzy c-means, clustering oscillations were highly reduced following similar disturbances. The research examined the control of the transmission line powers with the title of control analysis of transmission line power by UPFC [9].

Another study was conducted using a new method to control D-UPFC without delay in power grids. The most benefits of this method are reducing the time delay as much as possible and omitting distortion from the compensated voltage [10]. A study was presented in [11] to examine the angle and value of output terminal voltage of some generators, which are considered as the main parameters of the power systems stability, indicate that how much the transient stability of the grid is optimized after removing errors with considering UPFC presence and without UPFC presence. Research to improve voltage stability by UPFC by applying the algorithm of continuous power flow was performed. Simulation's findings will increase the power systems stability in using UPFC [12], [13].

In 2016, research in [14] was performed to examine a specific way. The optimization of the solar energy location is performed based on a grid with a similar cable cross-section. However, we investigate the technical and economic effects of the cable cross-section, operation hours and power periods and the opportunity of using several solar panels with multi parted grids. The source point, which corresponds to the minimum total finance, is considered an optimized load distribution. It can be named optimized (OVC). The research was performed in [15] presents an advanced element of FACTS named distributed power flow regulator was adapted with UPFC conception. DFPC could be treated as a UPFC with an absent DC bus. A significant number of series converters create redundancy that increases system stability. D-FACTS are floating to the ground, and no separation with huge voltage among phases is not required. The MATLAB environment examines the function of DPFC. Another research performed in [16] that the electrification to rural areas is possible by reducing the transmission drop. The authors in [16] suggested the combining FACTS controller with the transmission system. It can estimate the performance and function of the transmission grid. The dynamic performance of the power grid could be investigated with and without UPFC. The optimal allocation of UPFC for transmission network and enhancing the electrical network's dynamic performance had been discussed using genetic algorithm in [17], [18].

The study's novelty resides in presenting a modified particle swarm optimization algorithm with the N.R method for optimal allocation of unified power flow controller in an electrical network applied on IEEE 30 buses as a case study. This study focused on the functions and benefits of UPFC for the power system, the corresponding effects on transient stability. MATLAB numerical simulation R2019b has been performed on IEEE 30 buses.

The rest of this study is prepared as: the research method for modelling of UPFC was described in section 2. Section 3 controls terminal voltage, UPFC compensation control, phase shift control, multi- 
function control, and control of the power flow in overloaded lines. The process for adopting UPFC has been clarified in section 4. Newton-Raphson power flow results had been discussed in part 5. Results and discussion prepared in section 6. Finally, dedications are shown in section 7.

\section{RESEARCH METHOD}

The principle of UPFC is working in the existence of VSC on both ends [19]. The UPFC can limit the moment and the direction of power flow in the grid by the relation output voltage of VSC as magnitude and phase angle $V_{v R} \angle \boldsymbol{\delta}_{v \boldsymbol{R}}$ with AC voltage supply $V_{S} \angle 0$, as given in (1). So, the case of imaginary power can also be adjusted by calibrating VCR relation concerning to $V_{S} \angle \mathbf{0}$ as shown in (2), where it can be generated reactive power when $V_{v R}>V_{S}$ and it can be consumed when $V_{v R}<V_{S}$ [20].

$$
\begin{aligned}
& P=\frac{V_{S} V_{v R}}{X_{l}} \sin \delta v R \\
& Q=\frac{v_{S}^{2}}{X_{l}}-\frac{V_{S} V_{v R}}{X_{l}} \cos \delta v R
\end{aligned}
$$

From the schematic diagram of the unified power flow controller in Figure 1, one can notice two VSC labelled series, and parallel converter has functioned with a direct current bus. The DC-bus energy is transformed to AC and linked to the transmission line through a shunt- transformer. In fact, the parallel converter can work as the synchronous condenser to generate imaginary power to the AC network. Studying mathematical model requires examining the relation between the electric system and UPFC in normal condition. Figures 1 and 2 demonstrate a linear transmission diagram with resistance $r$, inductance $x, a$ UPFC, a voltage source of $V s$ the transmitter end and a voltage source of $V r$ the receiver is indicated in [21].

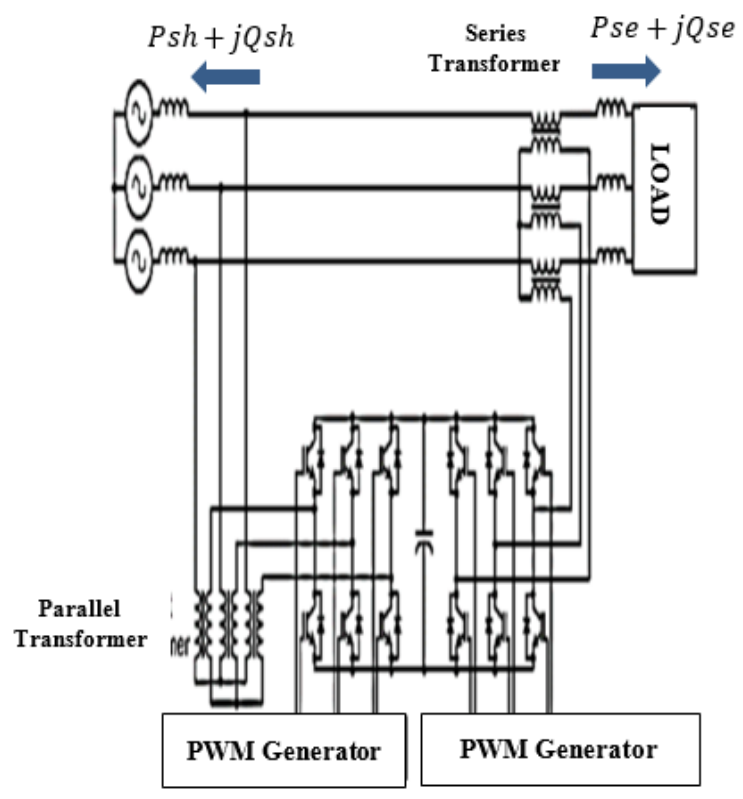

Figure 1. The power circuit of UPFC

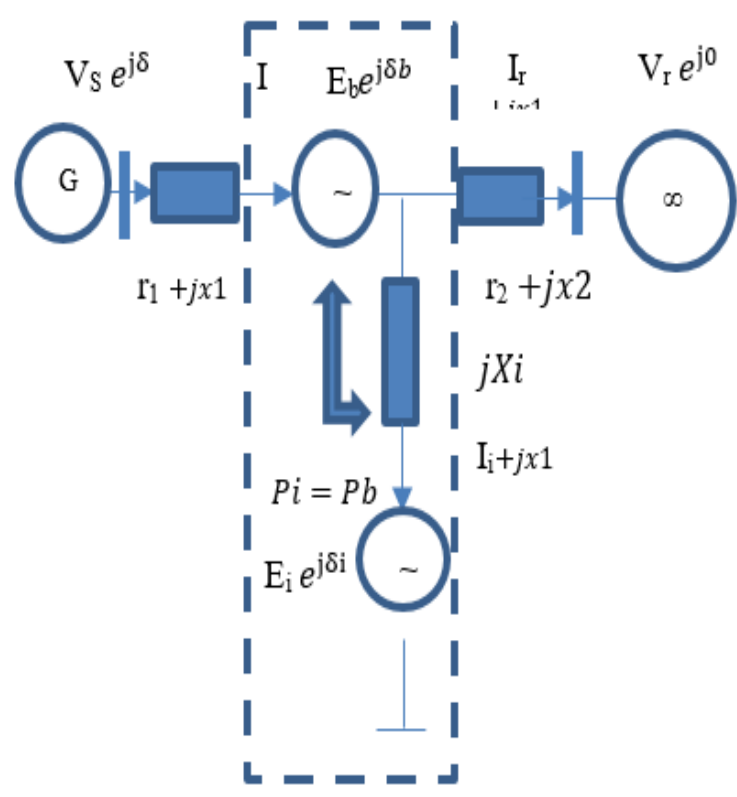

Figure 2. Modelling of a UPFC

\section{CONTROL OBJECTIVES}

The primary purpose of this paper to achieve the following main functions given below:

$\mathrm{CO}_{1}$ : Controlling UPFC terminal voltage: It can control the voltage with minimal steps like tap changing transformers.

$\mathrm{CO}_{2}$ : Multi-function command of UPFC: It can control the crossing power with several methods concurrently. Compensation is performed with terminal voltage control, series compensation of the line, and adjusting the phase shift angle.

$\mathrm{CO}_{3}$ : Optimizing power flow in the electrical power system.

It should analyze the UPFC equivalent circuit and specify most of the related equations [22]. 


\subsection{Voltage level maintaining}

The following equations illustrate voltage level maintenance:

$$
\begin{aligned}
& E i=V i(\cos \delta i+j \sin \delta i) \\
& E b=V b(\cos \delta b+j \sin \delta b) \\
& \operatorname{Re}\left\{-E_{i} I_{i}^{*}+-E_{b} I_{b}^{*}\right\}=0
\end{aligned}
$$

The transfer admittance matrix could be written as in (6):

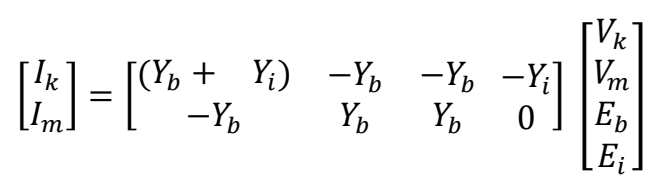

The equation of active and reactive power in sending and receiving buses $(k, m)$ are; [23]. At bus $k$ :

$$
\begin{aligned}
& P_{k}=V_{k}^{2} G_{k k}+V_{k} V_{m}\left[G_{k m} \cos \left(\theta_{k}-\theta_{m}\right)+B_{k m} \sin \left(\theta_{k}-\theta_{m}\right)\right]+V_{k} V_{b}\left[G _ { k m } \operatorname { c o s } \left(\theta_{k}-\right.\right. \\
& \left.\left.\delta_{c R}\right)+B_{k m} \sin \left(\theta_{k}-\delta_{b}\right)\right]+V_{k} V_{i}\left[G_{i} \cos \left(\theta_{k}-\delta_{i}\right)+B_{i} \sin \left(\theta_{k}-\delta_{i}\right)\right] \\
& Q_{k}=-V_{k}^{2} B_{k k}+V_{k} V_{m}\left[G_{k m} \sin \left(\theta_{k}-\theta_{m}\right)-B_{k m} \cos \left(\theta_{k}-\theta_{m}\right)\right]+V_{k} V_{b}\left[G _ { k m } \operatorname { s i n } \left(\theta_{k}-\right.\right. \\
& \left.\left.\delta_{b}\right)-B_{k m} \cos \left(\theta_{k}-\delta_{b}\right)\right]+V_{k} V_{i}\left[G_{i} \sin \left(\theta_{k}-\delta_{i}\right)+B_{i} \cos \left(\theta_{k}-\delta_{i}\right)\right] \\
& \text { At bus m: } \\
& P_{m}=V_{m}^{2} G_{m m}+V_{m} V_{k}\left[G_{m k} \cos \left(\theta_{m}-\theta_{k}\right)+B_{m k} \sin \left(\theta_{m}-\theta_{k}\right)\right]+V_{m} V_{b}\left[G _ { m m } \operatorname { c o s } \left(\theta_{m}-\right.\right. \\
& \left.\left.\delta_{b}\right)+B_{m m} \sin \left(\theta_{m}-\delta_{b}\right)\right] \\
& Q_{k}=-V_{m}^{2} B_{m m}+V_{m} V_{k}\left[G_{m k} \sin \left(\theta_{m}-\theta_{k}\right)-B_{m k} \cos \left(\theta_{m}-\theta_{k}\right)\right]+ \\
& V_{m} V_{b}\left[G_{m m} \sin \left(\theta_{m}-\delta_{b}\right)-B_{m m} \cos \left(\theta_{m}-\delta_{b}\right)\right]
\end{aligned}
$$

\subsection{Power flow in overloading lines}

To diminish the total power in lines, it was recommended to compute the actual and reactive power per line as in (11)-(12) [24].

$$
\begin{aligned}
& P_{G i}-P_{D i}=V_{i} \sum_{k=1}^{N_{B}} V_{j}\left[G_{K} \cos \left(\delta_{i}-\delta_{j}\right)+B_{K} \sin \left(\delta_{i}-\delta_{j}\right)\right] \\
& Q_{G i}-Q_{D i}=V_{i} \sum_{k=1}^{N_{B}} V_{j}\left[G_{K} \sin \left(\delta_{i}-\delta_{j}\right)+B_{K} \cos \left(\delta_{i}-\delta_{j}\right)\right]
\end{aligned}
$$

\subsection{Real and imaginary power losses}

By selecting the appropriate variable from the UPFC that will be inserted in the grid, it can attain the targets that will minimize the real and imaginary losses. The total actual and imaginary power loss can be computed as in (13)-(14) [25];

$$
\begin{aligned}
& \mathrm{P}_{\mathrm{L}}=\sum_{\mathrm{i}=1}^{\mathrm{N}_{\mathrm{L}}} \mathrm{i}\left[\mathrm{V}_{\mathrm{k}}^{2}+\mathrm{V}_{\mathrm{m}}^{2}-2 \mathrm{~V}_{\mathrm{k}} \mathrm{V}_{\mathrm{m}} \cos \left(\delta_{\mathrm{k}}-\delta_{\mathrm{m}}\right)\right] \\
& \mathrm{Q}_{\mathrm{L}}=\sum_{\mathrm{i}=1}^{\mathrm{N}_{\mathrm{L}}} \mathrm{B}_{\mathrm{i}}\left[\mathrm{V}_{\mathrm{k}}^{2}+\mathrm{V}_{\mathrm{m}}^{2}-2 \mathrm{~V}_{\mathrm{k}} \mathrm{V}_{\mathrm{m}} \sin \left(\delta_{\mathrm{k}}-\delta_{\mathrm{m}}\right)\right]
\end{aligned}
$$

\subsection{Construction of modified particle swarm optimization}

Each bird's flying normalizes its position, giving a specific experiment, creating the best location done by itself and its neighbouring birds [26], [27]. According to the fundamentals of particle swarm optimization (PSO), one of its applications used for optimal allocation of UPFC conducting with the electrical power system. This algorithm based on birds gets about round multidimensional space expecting an optimal result. In fact, there are two significant best results. The first one so-called personal best, and the second one socalled global best [28]. Three steps used to calculate the objective function are summarized as:

Step 1 : Present position and speed.

Step 2 : Distance between the present location and personal best. 
Step 3 : Distance between the present location and the global best.

Now, let us consider the particle's location, $l_{p}$ and speed $s_{p}$ could be modified (15) and (16).

$$
\begin{aligned}
& s_{p}^{i+1}=W s_{p}^{i}+m_{1} \text { rand }^{\times}\left(\text {pbest }_{p}-v_{p}^{i}\right)+m_{2} \text { rand }^{\times}\left(\text {gbest }_{p}-v_{p}^{i}\right) \\
& l_{p}^{i+1}=l_{p}^{i}+s_{p}^{i+1}
\end{aligned}
$$

Where $m_{1}, m_{2}$ are positive design constants, rand indicates to random number bounded $[0,1]$. $W$ is defined as wight inertia. The best location scenario's goal resides in minimizing the electrical system's global real and imaginary power losses (13). The actual power loss index was given [29]:

$$
P_{\text {Loss }, \text { index }}=\left(\frac{P_{\text {Loss }, w U P F C}}{P_{\text {Loss }, \text { woUPFC }}}\right) \times 100 \%
$$

also,

$$
Q_{\text {Loss, index }}=\left(\frac{Q_{\text {Loss, }, \text { WUPFC }}}{Q_{\text {Loss }, \text { woUPFC }}}\right) \times 100 \%
$$

where $P_{\text {Loss, wUPFC }}$ is the actual power loss with UPFC, $P_{\text {Loss,woUPFC }}$ is the actual power loss without UPFC, $Q_{\text {Loss,wUPFC }}$ is the imaginary power loss with UPFC and $Q_{\text {Loss ,woUPFC }}$ is the imaginary power loss without UPFC.

The modified particle swarm optimization algorithm for the optimal allocation of UPFC device on IEEE 30 buses is given in the following steps:

Step 1 : Start the modified PSO algorithm and read bus data, line data and tolerance through N.R.

Step 2 : Run the program to generate an initial population of particles.

Step 3 : Compute actual power loss per particle

Step 4 : Set the current $i_{\text {set }}$.

Step 5 : Set the global best current $g_{\text {beet }}$.

Step 6 : Bring up-to-date the velocity and position of each particle.

Step 7 : If $i=$ maimume iteration and the time complete, stop modified PSO running and write the best solution, else set new iteration, $i=i+1$

\section{PROCESS FOR ADOPTING UPFC}

Insertion UPFC to the grid treated the most difficulties that are exposed to the electrical network. It will be attained by selecting the best constraints of the UPFC, which can minimize the overload line and make the voltage within the permissible range [30]. The following procedure is summarized in:

a. Considering MATLAB programming R2019b to describe the lines and buses data of IEEE-30 buses also the UPFC constraint and solve the system in Newton Raphson technique.

b. Applied UPFC device in particle swarm optimization to restrict the overloaded lines.

c. Assume the system enforced a rise in electrical load (7\%, 14\%, 21\%).

d. Electing the appropriate constraints of UPFC and optimal location.

e. It can reduce the overloaded lines, regulate real and imaginary power flow, and control the voltage in each bus, dynamic composition.

f. One of the critical issues in grids is the islanding phenomenon. Islanding is a condition that a part of a grid contains a part of the load separated from the grid while it has electricity.

\section{NEWTON-RAPHSON POWER FLOW RESULTS}

Newton-Raphson method is a sequential calculation adopting a primary condition of the first-order equation given by series extension. Figure 3 clarifies the power line diagram of IEEE-30 buses. N-R using bus admittance matrix in either first or second-order has been evaluating as the optimal solution for reliability evaluation. IEEE 30-buses network consists of:
a. Six generators.
b. Forty-one Transmission lines.
c. Four transformers.
d. Two parallel capacitors.
e. Twenty-one loads and thirty buses 
The present research has simulated the mentioned processes adopting MATLAB environment R2019b adopting IEEE 30 buses as a case study and performance evaluation obtained through analyses, simulation or measurements.

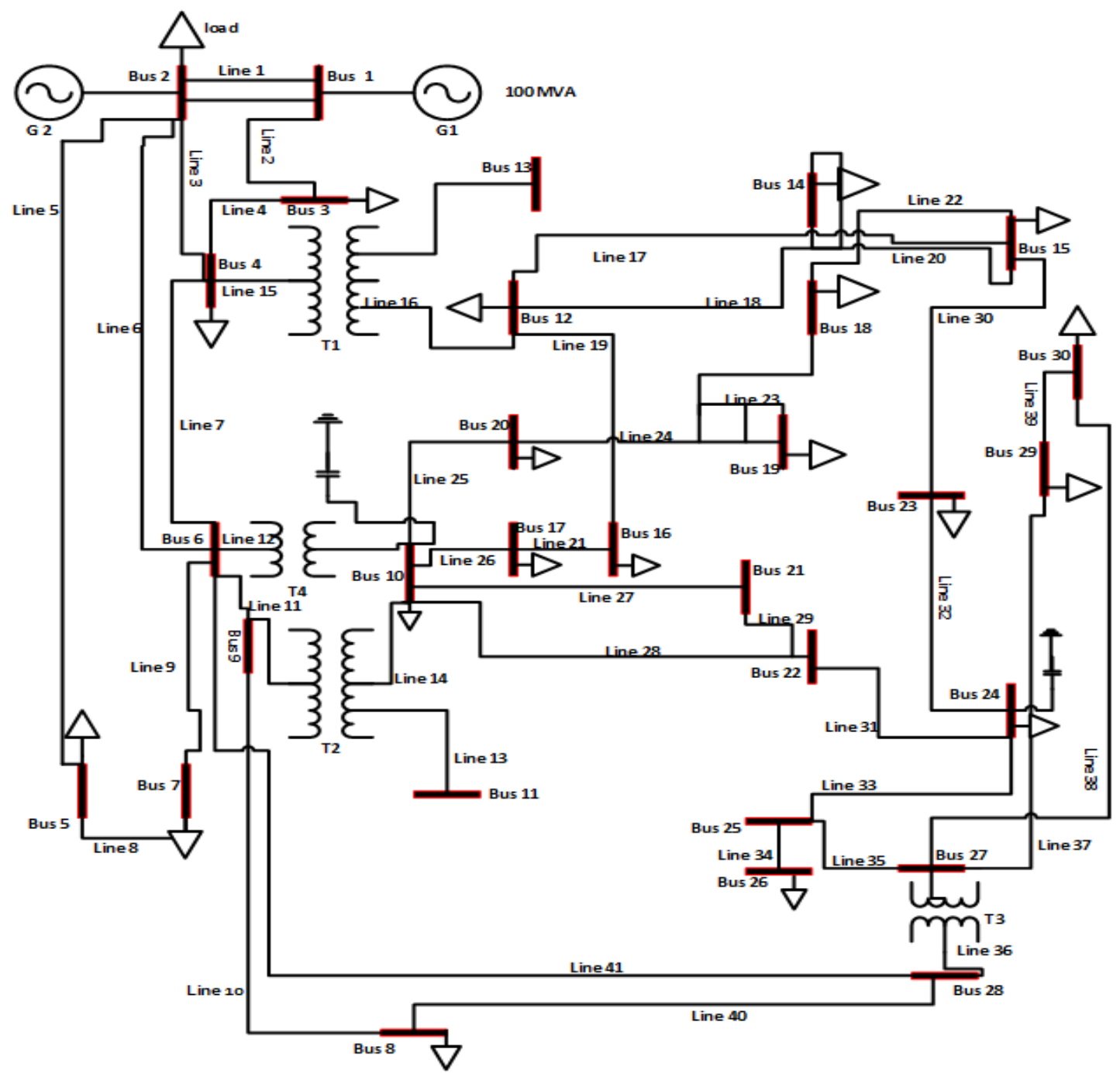

Figure 3 . The arrangement of network case study

\section{RESULTS AND DISCUSSION}

\subsection{Optimal allocation of UPFC}

In this study, the first contribution is studying the effect of inserting UPFC into the transmission system, considering the normal state, i.e., real and imaginary electrical load power. The second state tries to augment the total load power in three steps, as listed in Table 1. In these cases, it can be computed total real and imaginary power losses for transmission system taking into consideration insertion and without insertion UPFC and try to discover how the insertion of UPFC could increase the loadability and minimize overloading on the lines using particle swarm optimization technique as listed in Tables 1 and 2. The best allocation and number of UPFC are selecting to sustain DC bus voltage within the permissible boundary, falling the power in overloaded lines and decreasing the total losses. One can focus on Table 2 and observes the line linked between buses 1 and 2 most visible to overload state where it seems in most cases with growth in actual and reactive power losses.

The decrease in actual and imaginary losses with insertion UPFC between $(2,6)$ is clarified in Figures 4 and 5. UPFC starts to insert real power to bus 2 to reimburse the power demand in power lines linked between buses 1 and 2 and decrease from overloading and electrical stresses. On the other hands, UPFC decreases the total actual and imaginary power loss index in most cases, as illustrated in Figure 6 
compared to and without UPFC. One UPFC could not diminish from overloading in power lines, so using 2 NUPFC in various locations enhanced loadability and reduced power losses.

Table 1. Optimization results using PSO

\begin{tabular}{ccccc}
\hline Cases & Loading (MW) & \multicolumn{2}{c}{ Total Power Line Losses } & Overloading Lines \\
& & P (MW) & Q (MVar) \\
\hline Usual Case & 177.778 & 5.464 & 10.524 & Bus (1-2) \\
Load Increased by (7\%) & 190.225 & 5.846 & 11.261 & Bus (1-2), Bus (6-8) \\
Load Increased by (14\%) & 202.667 & 6.229 & 11.997 & Bus (1-2), bus (6-8) and bus (2-6) \\
Load Increased by (21\%) & 215.111 & 6.611 & 12.734 & Bus (1-2), bus (2-6), Bus (4-6), and Bus (6-8) \\
\hline
\end{tabular}

Table 2. Optimization results with a unified power flow controller

\begin{tabular}{|c|c|c|c|c|c|}
\hline \multirow[t]{2}{*}{ Cases } & \multirow{2}{*}{$\begin{array}{l}\text { Number of } \\
\text { UPFC and } \\
\text { Location }\end{array}$} & \multirow[t]{2}{*}{ UPFC Size } & \multicolumn{2}{|c|}{ Total Power Line Losses } & \multirow{2}{*}{$\begin{array}{l}\text { Overloading } \\
\text { Lines }\end{array}$} \\
\hline & & & $\mathrm{P}(\mathrm{MW})$ & Q (MVar) & \\
\hline Usual Case & $\begin{array}{l}\text { NUPFC }=1 \\
\text { Bus }(2-6)\end{array}$ & $\begin{array}{l}\mathrm{Vb}=0.155, \delta \mathrm{b}=-0.022 \\
\mathrm{Vi}=0.004, \delta \mathrm{i}=0.008 \\
\mathrm{XL}=0.003\end{array}$ & 3.838 & 6.248 & Nothing \\
\hline Increased by $(7 \%)$ & $\begin{array}{c}\mathrm{NUPFC}=1 \\
(2-6)\end{array}$ & $\begin{array}{l}\mathrm{Vb}=0.0423, \delta b=-0.0183 \\
\mathrm{Vi}=0.0, \delta \mathrm{i}=0.0, \mathrm{XL}=0.003\end{array}$ & 2.914 & 4.632 & Nothing \\
\hline Increased by $(14 \%)$ & $\begin{array}{l}\text { NUPFC = } 2 \\
\text { Bus }(6-7) \\
\text { Bus }(4-3)\end{array}$ & $\begin{array}{l}\mathrm{Vb} 1=0.0028, \delta \mathrm{b} 1=-0.003 \\
\mathrm{Vi} 1=0.0, \delta \mathrm{i} 1=0.0 \\
\mathrm{Vb} 2=0.0089, \delta \mathrm{b} 2=-0.0057 \\
\mathrm{Vi} 2=0.0089, \delta \mathrm{i} 2=0.0103 \\
\mathrm{XL}=0.003\end{array}$ & 3.319 & 5.098 & Nothing \\
\hline Increased by $(21 \%)$ & $\begin{array}{l}\text { NUPFC }=2 \\
\text { Bus }(6-7) \\
\text { Bus }(4-3)\end{array}$ & $\begin{array}{l}\mathrm{Vb} 1=0.0014, \quad \delta \mathrm{b} 1=-0.0004 \\
\mathrm{Vi1}=0.0092, \delta \mathrm{i} 1=0.0011 \\
\mathrm{Vb} 2=0.0162, \delta \mathrm{b} 2=-0.0163 \\
\mathrm{Vi2}=0.0096, \delta \mathrm{i} 2=0.0015\end{array}$ & 3.202 & 4.968 & Nothing \\
\hline
\end{tabular}

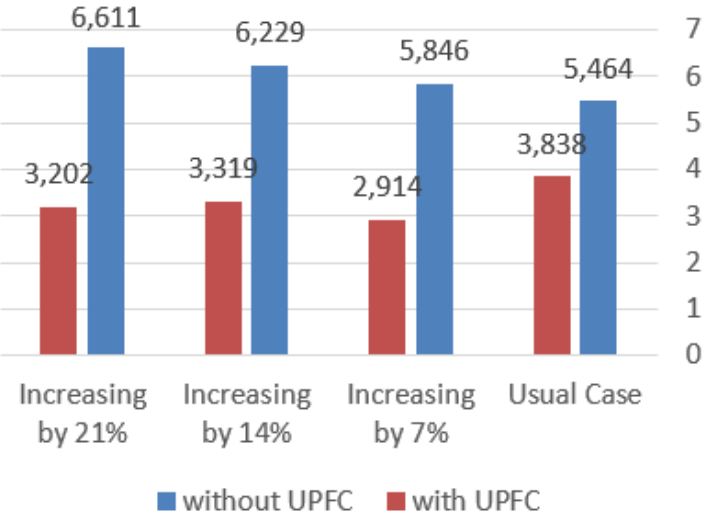

Figure 4. Actual power losses between bus (1-2)

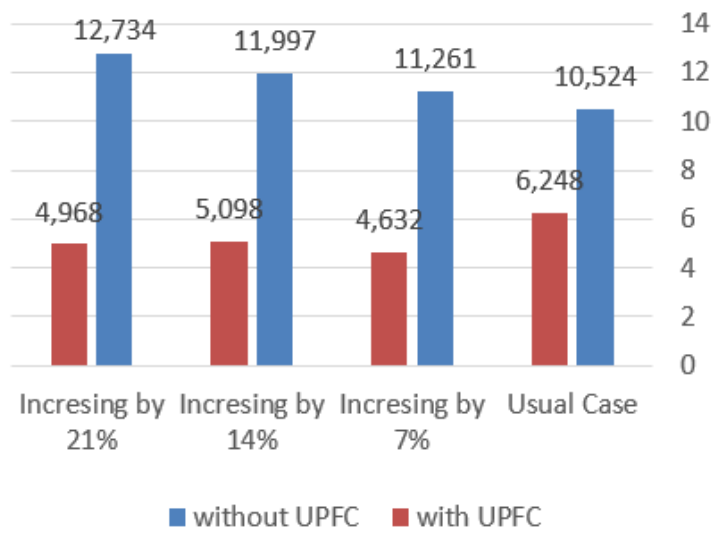

Figure 5. Imaginary power losses between bus (1-2)

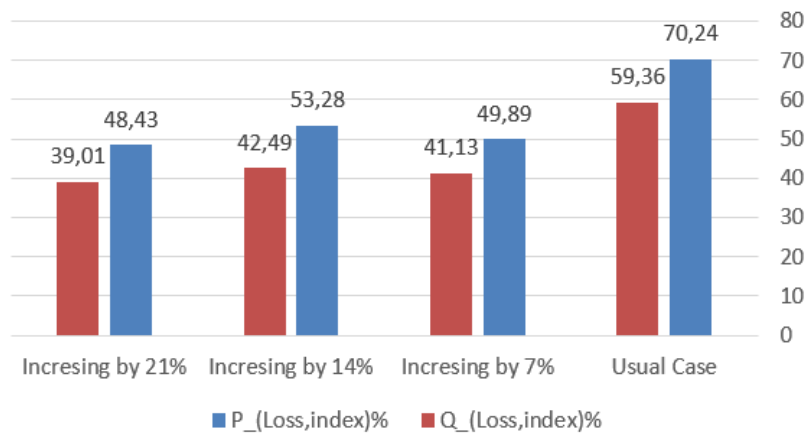

Figure 6. Real and Imaginary power loss index in the area between bus (1-2) 


\subsection{Dynamic response for transient stability}

If a three-phase disturbance has occurred, a circuit breaker and a UPFC unit are blocked between bus (1-2). The given source of active power is changed to 6 p.u at $5 \mathrm{sec}$. UPFC is applied to the network at $2 \mathrm{sec}$. It is also entered at $7 \mathrm{~s}$ to confirm the UPFC performance and achieve an accurate and imaginary power-seeking electrical network. The simulation results showed that UPFC is cleared from (0-2) s, and it will be coming into the system after the second 2. After the second 2, the UPFC is located at the circuit, the voltage will be approached to its reference values, and it will keep the stability after applying the disturbance. The disturbance and islanding mode effect can also be observed in the network's potential profile in time interval [7], [12] sec., respectively. The power flow will approach its reference value and will keep stability after applying the disturbance. Before the second 5, the reference power was six p.u, but the output power could not track the reference power because of applying UPFC in the second 2. At seven sec., the applied three-phase disturbance is well repulsed. One of the generators is out of the electrical network, and a massive shock has been applied to the network at $12 \mathrm{~s}$. Currently, a UPFC has been able to create smooth conduction and stabilize the electrical network, as shown in Figure 7.

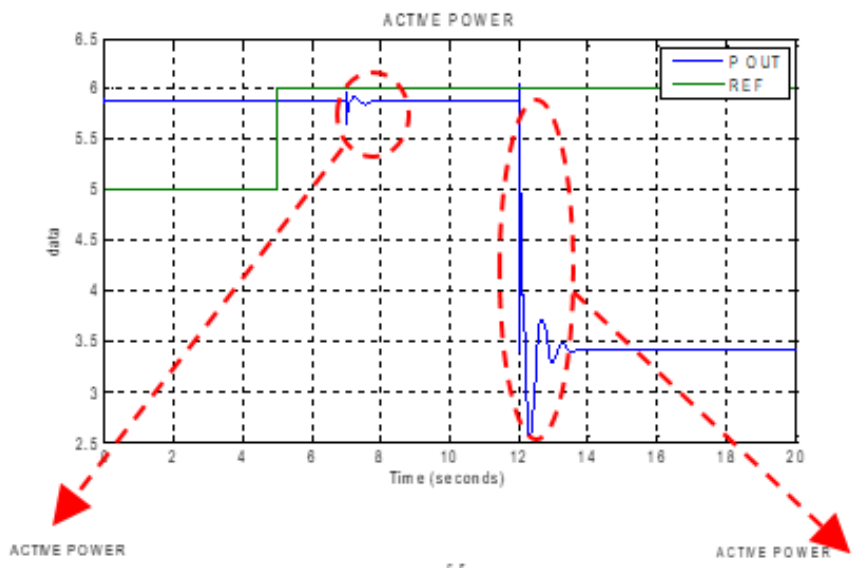

(a)

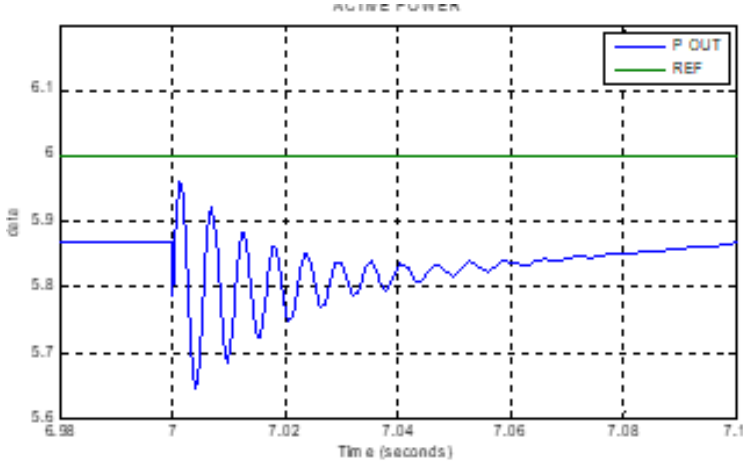

(b)

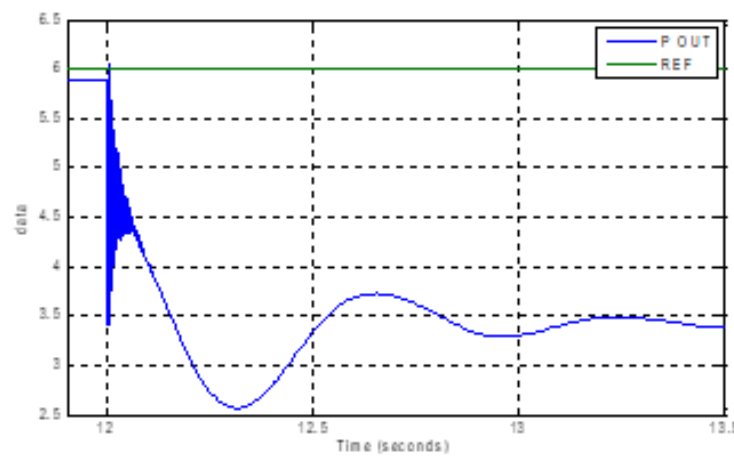

(c)

Figure 7. The real power diagram during islanding mode; (a) real power for all system, (b) real power for fault occurs, (c) real power for islanding mode

\section{CONCLUSION}

This paper presents a study on IEEE - 30 buses as a case study, based on controlling the function of UPFC. UPFC uses voltage regulation and a power flow controller to make the power system efficient and reliable. The case study results illustrate that the number of UPFC increased with load increased by (14\% and $21 \%$ ). One UPFC could not diminish from overloading in power lines, so using 2 NUPFC in various locations enhanced loadability and reduced power losses. In conclusion, this study has two contributions. The first contribution is specifying an optimal allocation of UPFC in the electrical power networks. The second contribution is improving the transient stability of power systems adopting UPFC. At last, we conclude that 
conducting UPFC is better for improving transient stability and critical clearing times. In the future, a new generation of FACTS should be analyzed, discussed and compared the obtained results with the current study.

\section{ACKNOWLEDGEMENTS}

The authors wish to acknowledge assistance from university staff in accomplishing the current manuscript.

\section{REFERENCES}

[1] H. Hussein, G. Salman, M. Hasan, "Phase Measurement Units-Based FACT's Devices for the improvement of power systems networks controllability," International Journal of Electrical and Computer Engineering (IJECE), vol. 8, no. 2, pp. 888-899, 2018, doi: 10.11591/ijece.v8i2.pp888-899 .

[2] S. S. Reddy, "Optimal Placement of FACTS Controllers for Congestion Management in the Deregulated Power System," International Journal of Electrical and Computer Engineering (IJECE), vol. 8, no. 3, pp. 1336-1344, 2018, doi: 10.11591/ijece.v8i3.pp1336-1344.

[3] B. Prity, and S. Amit, "Comparison Between SVC and STATCOM FACTS Devices for Power System Stability Enhancement," International Journal on Emerging Technologies, vol. 4, no. 2, pp. 101-109, 2013

[4] P. Majid, N.Brij, and R. Parviz, "A Nonlinear Control Method for SSSC to Improve Power System Stability," 2006 International Conference on Power Electronic, Drives and Energy Systems, 2006, pp. 1-7, doi: 10.1109/PEDES.2006.344230.

[5] C. Papadimitriou, N. Kleftakis, and N. D. Hatziargyriou," A Novel Islanding Detection Method for Microgrids Based on Variable Impedance Insertion," Electric Power Systems Research, vol. 121, pp. 58-66, 2015, doi: $10.1016 /$ j.epsr.2014.12.004

[6] A. N. Alsammak and H. A. Mohammed, "A Literature Review on the Unified Power Flow Controller UPFC," International Journal of Computer Applications, vol. 182, no.12, pp. 23-29, 2018.

[7] M. Takeshita, H. Sugihara, "Effect of Fault Current Limiting of UPFC for Power Flow Control in Loop Transmission," IEEE/PES Transmission and Distribution Conference and Exhibition, vol. 3, 2002, pp. 2032-2036, doi: 10.1109/TDC.2002.1177773.

[8] A. M. Dejamkhooy, M. Banejad, N. Talebi, "Fuzzy Logic Based UPFC Controller for Damping Low-Frequency Oscillations of Power Systems," 2008 IEEE 2nd International Power and Energy Conference, 2008, pp. 85-88, doi: 10.1109/PECON.2008.4762450.

[9] L. N. Tripathy, S. R. Samantaray, P. K. Dash, "A Fast Time-Frequency Transform-Based Differential Relaying Scheme for UPFC Based Double-Circuit Transmission Line," International Journal of Electrical Power \& Energy Systems, vol.77, pp. 404-417, 2016, doi: 10.1016/j.ijepes.2015.11.032.

[10] G. Kenne, R. Kuate, A. Fombu, J. Ndongmo, and H. Fotsin, "A New Hybrid UPFC Controller for Power Flow Control and Voltage Regulation Based on RBF Neurosliding Mode Technique," Advances in Electrical Engineering, vol. 2017, pp. 1-11, 2017, doi: 10.1155/2017/7873491.

[11] V. Gupta, "Study and Effects of UPFC and its Control System for Power Flow Control and Voltage Injection in a Power System," International Journal of Engineering Science and Technology, vol. 2, no.7, pp. 2558-2566, 2010.

[12] R. Kalaivani, and V. Kamaraj, "Enhancement of Voltage Stability by Optimal Location of SVC using Genetic Algorithm and Particle Swarm Optimization," American Journal of Engineering and Applied Sciences, vol. 5, no. 1 , pp. $70-77,2012$, doi: 10.3844/ajeassp.2012.70.77.

[13] B. Banhthasit, C. Jamroen, and S. Dechanupaprittha, "Optimal Generation Scheduling of Power System for Maximum Renewable Energy Harvesting and Power Losses Minimization," International Journal of Electrical and Computer Engineering (IJECE), vol. 8, no. 4, pp. 1954-1966, 2018, doi: 10.11591/ijece.v8i4.pp1954-1966.

[14] A. Cardenas, K. Agbossou, and M. L. Doumbia, "Islanding Detection Method for Multi-Inverter Distributed Generation," Journal of Electromagnetic Analysis and Applications, vol. 1, no. 3, pp. 170-180, 2009, doi: 10.4236/jemaa.2009.13026.

[15] M. M. Marei and M. H. Nawer, "Power losses reduction of power transmission network using optimal location of low-level generation," International Journal of Electrical and Computer Engineering, vol.10, no. 6, pp. 5586-5591, Dec. 2020, doi: 10.11591/ijece.v10i6.pp5586-5591.

[16] B. Y. Reddy, "Development of Distributed Power Flow Controller for Improved Performance of the Power System Network," Indian Journal of Science and Technology, vol. 8, no. 23, pp. 1-5, 2015, doi: 10.17485/ijst/2015/v8i23/72051.

[17] S. Krishnamurthy, and G. Noudjiep, "Performance Analysis and Improvement of a Power System Network using a Unified Power Flow Controller," 2015 International Conference on the Industrial and Commercial Use of Energy (ICUE), 2015, pp. 306 -312, doi: 10.1109/ICUE.2015.7280283.

[18] A. Ghassan, H. Mohammed, N. Ali, "Implementation Optimal Location and Sizing of UPFC on Iraqi Power System Grid $(132 \mathrm{kV})$ using Genetic Algorithm," International Journal of Power Electronics and Drive System (IJPEDS), vol. 9, no. 4, pp. 1607-1615, 2018, doi: 10.11591/ijpeds.v9n4.pp1607-1615.

[19] M. Najeeb, M. Mansor, H. Feyad, E Taha, G. Abdullah, "An Optimal LFC in Two-Area Power Systems using a Meta-Heuristic Optimization Algorithm," International Journal of Electrical and Computer Engineering (IJECE), vol. 7, no. 6, pp. 317-325, 2017, doi: 10.11591/ijece.v7i6.pp3217-3225.

[20] M. Sarkar, "Effect of UPFC Allocation On Transmission System Power Loss," 2013 International Conference on Energy Efficient Technologies for Sustainability, 2013, pp. 1185-1188, doi: 10.1109/ICEETS.2013.6533555. 
[21] K. Takkolu, T. Kumar, and G. Prasad, "Power Flow Control and Voltage Profile Improvement Using Unified Power Flow Controller (UPFC) in a Grid Network," International Journal of Electronics and Electrical Engineering, vol.4, no. 6, pp. 482-487, 2016, doi: 10.18178/ijeee.4.6.482-487.

[22] S. Khanchi, V. K. Garg, "Unified Power Flow Controller: A Review," International Journal of Engineering Research and Applications, vol. 3, no. 4, pp.1430-1435, 2013.

[23] N. G. Hingorani and L. Gyugyi, "Understanding FACTS Concepts and Technology of Flexible AC Transmission Systems," New York: IEEE Press, 2000.

[24] E. Acha, R. Esquivel, P. Ambriz, C. Angeles, "FACTS Modeling and Simulation in Power Networks," John Wiley and Sons LTD, England, 2004.

[25] A. Aktas, K. Erhan, S. Ozdemir, and E. Ozdemir, "Experimental Investigation of a New Smart Energy Management Algorithm for a Hybrid Energy Storage System in Smart Grid Applications," Electr. Power Syst. Res., vol. 144, no. 3, pp.185-96, 2017.

[26] M. Saadi, R. Mejeed, and H. Hameed, "Analysis of Diyala Power Network for the Distributed Feeders Between Iraq and Iran: 132 kV Baquba-Sarbilzahab," International Review of Electrical Engineering, vol. 14, no. 5, pp. 359370, 2019, doi: 10.15866/iree.v14i5.17122.

[27] V. Z. Manusov, P. V. Matrenin, and N. Khasanzoda, "Swarm Algorithms in Dynamic Optimization Problem of Reactive Power Compensation Units Control," International Journal of Electrical and Computer Engineering (IJECE), vol. 9, no. 5, pp. 3967-3974, 2019, doi: 10.11591/ijece.v9i5.pp3967-3974.

[28] A. N. Hussain, and A. A. Ismail, "Operation Cost Reduction in Unit Commitment Problem using Improved Quantum Binary PSO Algorithm," International Journal of Electrical and Computer Engineering (IJECE), vol. 10, no. 2, pp. 1149-1155, 2020, doi: 10.11591/ijece.v10i2.pp1149-1155.

[29] C. Shang, D. Srinivasan, and T. Reindl, "An Improved Particle Swarm Optimization Algorithm Applied to Battery Sizing for Stand-Alone Hybrid Power Systems," Electrical Power and Energy Systems, vol. 8, no. 4, pp. 104-117, 2016, doi: 10.1016/j.ijepes.2015.07.009.

[30] S. Zare, M. Rahmanpoori, and A. H. Khazali, "A New Active Islanding Detection Method of DG," 22nd International Conference and Exhibition on Electricity Distribution (CIRED 2013), 2013, doi: $10.1049 / \mathrm{cp} .2013 .0545$. 